\title{
Excluídos em nome da lei: práticas racistas no sistema jurídico da Guiana Inglesa ${ }^{1}$
}

Excluded in the Name of the Law: Racist Practices in the Legal System of British Guiana

\author{
João Italo de Oliveira e Silva*
}

Resumo: A população de origem asiática no continente americano conviveu, no século XIX, com políticas restritivas, discursos preconceituosos e uma contínua estigmatização. O racismo estrutural consistiu em uma realidade que promoveu a exclusão política, econômica e jurídica, sempre calcadas em uma ideologia profundamente enraizada. Este artigo analisa como a legislação e o processo político conseguiram excluir indianos e chineses na colônia britânica da Guiana Inglesa. Partimos de memórias de ex-funcionários públicos, de cartas-denúncia, do relatório da Comissão de Inquérito e de outros documentos para perceber o papel do judiciário na exclusão dessas populações. Os textos de Sílvio de Almeida e de Grada Kilomba servem como base teórica para a compreensão do racismo estrutural dentro do Império Inglês.

Palavras-chave: Racismo estrutural; Imigração chinesa; Guiana Inglesa.
Abstract: The population of Asian origin in the American continent lived, in the 19th century, with restrictive policies, prejudiced speeches, and continuous stigmatization. Structural racism was a reality that promoted political, economic, and legal exclusion, always based on a deep-rooted ideology. This paper examines how legislation and the political process succeeded in excluding Indians and Chinese in the British colony of English Guiana. We start from the memories of former civil servants, letters of complaint, the report of the Commission of Inquiry, and other documents to understand the role of the judiciary in the exclusion of these populations. The texts by Silvio de Almeida and Grada Kilomba serve as the theoretical basis for understanding structural racism within the English Empire.

Keywords: Structural Racism; Chinese Immigration; British Guiana.

\footnotetext{
* Universidade Federal de Minas Gerais (UFMG), MG, Brasil. joao_italo@hotmail.com <https://orcid. org/0000-0003-1548-2279>
} 
Em meados da década de 1860, o juiz George William Des Voeux determinou que uma mulher grávida de origem indiana não fosse presa por se negar a realizar as suas tarefas diárias. A acusação alegava que a mulher tinha sido negligente com as tarefas rotineiras do seu trabalho e, por isso, deveria ser punida com a prisão. A decisão favorável do juiz à mulher causou indignação ao administrador da fazenda, que recorreu a esferas mais altas, incluindo o chefe de justiça da região. A decisão foi mantida pelo magistrado, o que aumentou ainda mais a indignação dos latifundiários da região, que utilizaram de sua influência para retirar o Chief of Justice do cargo sob a acusação de “indiscrição” (Des Voeux, 1871 [1869], p. 383).

George William Des Voeux, juiz entre os anos de 1863 e 1869 na Guiana Inglesa, escreveu uma carta-denúncia na qual relatava as condições precárias dos imigrantes asiáticos na colônia inglesa. Para além dos abusos de poder perpetrados pelos fazendeiros, as condições das moradias eram precárias e a água oferecida aos imigrantes era péssima. Des Voeux dedicou especial atenção à interferência dos grandes proprietários na execução da justiça. O magistrado apresentou um cenário no qual os fazendeiros exerciam influência sobre as instituições estatais, sendo que ninguém, nem mesmo o governador, se contrapunha a essa classe. Os juízes que se atreviam a apresentar uma acusação corriqueira contra um capataz despertariam a fúria dos latifundiários (Des Voeux, 1869, p. 389).

A Guiana Inglesa era responsável, na década de 1850 , por $25 \%$ da produção de açúcar do Caribe inglês, porcentagem que amontou a 40\% no final dos anos de 1880. A produção desta colônia ficava atrás na região apenas de Cuba, e chegou a representar 15\% da produção mundial do produto (Lai, 1993, p. 11). A região de Demerara, que incluía o principal porto e capital da colônia, Georgetown, liderava a produção de açúcar no país. As colônias de Demerara e Essequibo haviam sido reunidas em 1831, pelos britânicos, para a formação da Guiana Inglesa.

A região foi colônia holandesa até as primeiras décadas do século XIX e o sistema político holandês permaneceu em vigor na colônia inglesa até o ano de 1928, quando o governo inglês estabeleceu o sistema de Crown Colony. A Court of Police exercia funções do legislativo e do executivo, com a supervisão do Governador da colônia. A maioria dos membros da Court of Police eram nomeados pelo governador e o restante era escolhido pelo College of Kiezers. 
Os Kiezers, como eram conhecidos, eram eleitos dentro de um grupo restrito baseado na posse de terras. Os latifundiários ligados ao plantio de açúcar dominavam o Court of Police e o College of Kiezers (Anderson et al., 2020, p. 340).

Os latifundiários exerciam influência em órgãos importantes da colônia e, segundo Des Voeux, também tinham poder sobre os juízes enviados pela Inglaterra. $\mathrm{O}$ juiz relatou uma onda de represálias dos latifundiários, que variava desde insultos nas ruas e na corte a pequenos contratempos cotidianos, que tornaram a sua vida "algo intolerável". Em um livro de memórias, o juiz relatou que as pressões exercidas pelos latifundiários o motivaram a pedir a transferência para alguma outra colônia, mesmo que isso significasse uma remuneração menor. Em menos de dois meses, ele recebeu uma indicação para ocupar o Governo de Santa Lúcia, aceitando prontamente o convite (Des Voeux, 1948, pp. 99-100).

George Des Voeux denunciou o constrangimento dos representantes do poder judiciário inglês em Demerara ao tomarem decisões que contrariassem os latifundiários. O juiz ressaltou a conivência do governador que, mesmo ciente da situação, se recusava a assumir uma postura mais assertiva contra os latifundiários, que garantisse a autonomia das decisões dos funcionários da coroa. Em suas memórias, ele destacou o caso do chefe de justiça Joseph Beaumont, um magistrado destemido e imparcial, removido do cargo pelo governador. Beaumont havia anulado a decisão de muitos juízes por problemas triviais nos procedimentos legais. Algumas das suas decisões irritaram os latifundiários e, segundo Des Voeux, a pressão dessa classe levou à remoção de Beaumont (Des Voeux, 1958, pp. 95-96).

A carta-denúncia do ex-juiz descreve com riqueza de detalhes uma sociedade em que o racismo estrutural parece estar profundamente enraizado. As decisões do judiciário favoreceriam, em grande parte, os latifundiários, e os funcionários que se opunham a essa lógica eram afastados pelo governador. A etnia do réu afetava diretamente a decisão da corte. O cenário do século XIX já apresentava uma ideologia que, embasada pelas teorias raciais daquele período, categorizava e hierarquizava a sociedade de acordo com o fenótipo dos indivíduos. O racismo funcionava para além da ideologia e da teoria, e percorria os âmbitos político, econômico e jurídico da Guiana Inglesa na segunda metade do século XIX. Os três âmbitos citados viabilizavam, como argumenta Sílvio Almeida, a reprodução sistêmica de práticas racistas. 
Este artigo analisará o papel do sistema judiciário inglês para a conformação de um cenário no qual as elites econômicas brancas impunham práticas laborais ilegais a trabalhadores de origem asiática na Guiana Inglesa. O direito é entendido neste trabalho como "um mecanismo de sujeição e dominação", isto é, como "uma tecnologia de controle social utilizada para a consecução de objetivos políticos e para a correção do funcionamento institucional” (Almeida, 2020, pp. 83-84). Além da carta-denúncia de Des Voeux, analisaremos o panfleto do ex-juiz Joseph Beaumont, as memórias do ex-funcionário público britânico Henry Kirke, o relatório da Comissão de Inquérito enviado à colônia e a análise do inquérito realizada pelo enviado da Sociedade Abolicionista Britânica (British and Foreign Anti-Slavery Society), Edward Jenkins.

A atuação do poder judiciário pode ser entendida dentro de um sistema mais amplo de punição colonial, definido por Sherman como rede de coerção (coercive network). A punição extrapola a noção de encarceramento, incluindo multas e confisco de propriedades, por exemplo. Os julgamentos e as sanções fazem parte de um plano imperial e de estratégias de controle do cotidiano desses trabalhadores (Sherman, 2009, p. 669). O sistema jurídico serve, neste sentido, como uma ferramenta no sistema de opressão e dominação que os fazendeiros moviam contra os imigrantes asiáticos.

Os documentos apresentam as limitações e as dificuldades que os imigrantes asiáticos tinham para acessar a justiça. A burocracia, o custo financeiro, a diferença da língua e a interferência dos patrões eram obstáculos a serem superados. As barreiras legais e cotidianas eram acompanhadas de ideologia, que construía e reforçava uma série de estereótipos que colocavam em cheque a veracidade dos seus depoimentos. As decisões dos juízes eram, em sua quase totalidade, favoráveis aos grandes fazendeiros, segundo Des Voeux, que questionava a autonomia dos magistrados. A carta-denúncia e outros relatos apresentam um cenário em que trabalhadores indianos e chineses eram excluídos pelo sistema jurídico em vigor na Guiana Inglesa.

Discutiremos, nesse artigo, o papel da legislação e do direito na construção do racismo estrutural, no que tange às populações de origem asiática. Os documentos escolhidos discutem a condição do trabalhador indentured - a mão de obra que chegou no país a partir da década de 1840, por meio de contratos de trabalho. A denúncia de Des Voeux referia-se à realidade dessa mão de obra, e os demais documentos - o relatório da Comissão de Inquérito de 
1871 e o livro publicado por Joseph Beaumont - trataram das condições laborais desse grupo. Não analisaremos os mecanismos construídos por aquela sociedade para excluir as populações de origem africana e tampouco identificaremos os matizes que aproximam e diferenciam o racismo sofrido por chineses, indianos e africanos.

\section{LEGISLAÇÃO E DOMINAÇÃO}

Africanos, portugueses da Ilha da Madeira, chineses e indianos compunham a variada força de trabalho da Guiana Inglesa em meados do século XIX. A proibição do tráfico negreiro no Império Britânico e, consequentemente, da escravidão, em 1834, levou a Inglaterra a buscar alternativas para a escassez de trabalhadores. A mão de obra indiana foi a primeira opção, uma vez que o transporte dentro do Império era facilitado. Milhares de indianos migraram para diferentes colônias inglesas como Trinidad, Ilhas Maurício, Jamaica e Guiana, ao longo do século XIX e das primeiras décadas do século XX. Antes de embarcarem, esses trabalhadores assinavam contratos de trabalho ainda no porto de origem, concordando, assim, com a jornada de trabalho e com os salários. Os acordos duravam entre cinco a oito anos e, no caso dos indianos, garantiam o pagamento da passagem de volta ao seu país de origem. Caso o trabalhador resolvesse permanecer na colônia, o valor da passagem deveria ser entregue ao fim do primeiro contrato (Lai, 1993, p. 66).

Os trabalhadores de origem indiana supriram grande parte da demanda por mão de obra na Guiana Inglesa. Entre 1842 e 1870, mais de 42 mil indianos chegaram à colônia. A necessidade de pagamento da passagem de volta era arcada pela coroa inglesa, por meio de subsídios e impostos (Lai, 1993, p. 94). O Estado pagava aproximadamente dois terços desse custo com recursos vindos de taxas cobradas sobre os trabalhadores e com impostos sobre a terra e as exportações ${ }^{2}$. Os chineses apareceram como uma alternativa mais barata de mão de obra, uma vez que os contratos não estipulavam o pagamento da passagem de volta. Poucos chineses, no entanto, trabalhavam no Caribe inglês: apenas três mil no ano de 1861, sendo 85\% deles na Guiana Inglesa (Lai, 1998, pp. 12-13).

Tanto chineses como indianos chegavam à Guiana após terem assinado contratos de trabalho nos portos de origem (indentured labour). As cláusulas 
contidas nesses documentos eram bastante precisas e determinavam, por exemplo, a qualidade e quantidade de comida que deveria ser fornecida, o valor dos salários e a periodicidade dos pagamentos. Esses documentos garantiam acomodação, alimentação e assistência médica gratuita ao imigrante. Muitos países do continente americano utilizaram um sistema de trabalho regulado por contratos como uma forma de estabelecer um fluxo de trabalhadores livres, criando um contraponto em relação ao tráfico negreiro. Cuba e Peru receberam dezenas de milhares de chineses entre os anos de 1847 e 1874, que assinaram contratos ainda nos portos de origem ${ }^{3}$.

Os contratos serviam para diferenciar o recrutamento e o transporte de milhares de trabalhadores asiáticos para os mais diversos países do mundo do tráfico negreiro ${ }^{4}$. O historiador Jonathan Connolly percebeu mudanças em como a opinião pública inglesa percebia o emprego de trabalhadores contratados asiáticos (indentured labour) nas suas colônias. Na década de 1840, a imigração desses trabalhadores foi vista como um escândalo, uma "nova escravidão", mas também como um esforço para manter a estrutura econômica das sociedades emancipadas. Connolly percebeu uma consolidação gradual, ao longo da década de 1850, do apoio público ao trabalho indentured, baseada no sucesso econômico e na mudança do debate (Connolly, 2018, p. 118).

Muitos periódicos percebiam os imigrantes asiáticos como homens livres que voluntariamente teriam optado por trabalhar em outros países do mundo. O contrato servia, na prática, para restringir e limitar o campo de ação dos imigrantes, impedindo que eles abandonassem o seu contratante por oportunidades de trabalho mais bem remuneradas. Os imigrantes estavam presos aos contratantes por meio de uma dívida que incluía custos com passagem e adiantamentos de salários. O descumprimento das cláusulas ou o trânsito dos imigrantes sem o porte do documento eram motivos suficientes para a prisão desses trabalhadores. O porte dos contratos e de uma quantidade de outros documentos criava uma burocracia que dificultava a ascensão social e a livre mobilidade de chineses e indianos.

A legislação que regia as relações de trabalho dava amplos poderes aos empregadores e era conhecida como Lei Penal Trabalhista, o que já implica a função da punição e do controle. A legislação pode ser identificada como peça essencial nas redes de coerção apontadas por Sherman. Algumas atitudes cotidianas destacadas pelo antigo chefe de justiça da Guiana, Joseph Beaumont, 
revelam a existência de um sistema de coerção amplo e eficiente. Os regulamentos autorizavam, por exemplo, que os empregadores e seus funcionários "apreendessem sem mandato" imigrantes que fossem encontrados a mais de duas milhas das fazendas, sem estarem em posse de seus contratos ou de um documento que autorizasse o livre trânsito (Beaumont, 2011 [1871], p. 56). Essa lei apresenta, por exemplo, um obstáculo ao trabalhador que fosse a uma delegacia denunciar o seu patrão, fortalecendo as redes de coerção coloniais.

Joseph Beaumont, chefe de justiça da Guiana Inglesa entre 1863 e 1868, corroborou com as denúncias feitas por Des Voeux, seu contemporâneo de magistratura em Demerara. Beaumont escreveu o livro The New Slavery após ter sido impedido de prestar depoimento sobre a carta-denúncia de Des Voeux, em 1871. O ex-chefe de justiça saudou a iniciativa de Des Voeux e entendia que a Comissão de Inquérito era uma oportunidade de melhorar as práticas e as leis da Guiana Inglesa. Beaumont percebia as previsões de punição das Leis Trabalhistas como uma forma de forçar os imigrantes a trabalhar de acordo com a vontade e o ritmo determinados pelos patrões. A legislação cumpria o papel, segundo ele, de "subordinar as raças" (Beaumont, 2011, p. 37).

Os problemas evidenciados por Beaumont não seriam ocasionais ou oriundos de um excesso cometido por um funcionário. O juiz associava tais problemas à continuidade de práticas laborais construídas desde os anos da escravidão. O seu texto, inclusive, trazia algumas propostas, como a melhora do sistema de saúde, o pagamento de passagem de volta aos imigrantes chineses, o fortalecimento do Departamento de Imigração, a assistência aos imigrantes para acessarem os tribunais e a aplicação de penalidades contra os latifundiários e os seus funcionários. As Leis trabalhistas eram entendidas por ele como fontes de repressão e submissão aos imigrantes e, por isso, deveriam ser abolidas (Beaumont, 2011, pp. 35-36).

Joseph Beaumont esperava que a investigação estabelecida pela coroa inglesa, a Comissão de Inquérito, pudesse resolver os problemas imigratórios que, após a Carta de Des Voeux, não poderiam mais ser ignorados. A Comissão enviada para investigar a situação da Guiana inglesa não parecia compartilhar os mesmos anseios e expectativas do ex-Chefe de Justiça. O relatório da comissão reconheceu que as Leis Trabalhistas e a Lei de Vadiagem (Vagrancy Laws) eram duas armas nas mãos dos fazendeiros, cabendo-lhes impor o seu cumprimento. A Comissão reconheceu a imprecisão do conceito de "negligên- 
cia no trabalho", que poderia ser facilmente manipulado (Ithell, 1871, p. 186). Todavia, a solução apresentada pelos enviados ingleses não solucionava completamente os problemas.

O relatório da Comissão do Inquérito propôs a incorporação da prática do livret, um livro de registro de tarefas que todos os trabalhadores deveriam possuir, no qual seria semanalmente registrada a execução das cinco tarefas realizadas pelos imigrantes. O livret seria um documento oficial que poderia ser consultado toda vez que houvesse divergência entre empregador e empregado, quanto às questões de produtividade e negligência. $\mathrm{O}$ sistema teria provado a sua eficácia, segundo o relatório, em lugares como o Suriname e as colônias francesas no Caribe (Ithell, 1871, pp. 186, 195-196).

A proposta apresentada no relatório da Comissão de Inquérito não problematizava o fato de que o registro ou não das tarefas no caderno caberia ao empregador. Os critérios continuavam imprecisos e facilmente manipuláveis pelos proprietários da terra e, provavelmente, seriam referendados pelos magistrados. Os fazendeiros poderiam se negar a preencher a caderneta quando quisessem incriminar os trabalhadores, da mesma forma que se negavam a disponibilizar papéis que possibilitavam a livre circulação dos imigrantes. A proposta não resolvia de forma alguma o problema de assimetria de poder entre as partes, uma vez que os fazendeiros estavam em posse dos documentos que seriam transformados em provas em um suposto julgamento.

A sugestão de legislação presente no relatório pode parecer ingênua numa primeira análise, mas ela cumpre o papel das leis trabalhistas descrito por Beaumont: a subordinação das raças. Conforme lembrou Silvio Almeida, "as leis são uma extensão do poder político do grupo que detém o poder institucional". O direito não deixa de ser um meio de controle social que responde a objetivos políticos do grupo que elabora as legislações. Os regimes abertamente racistas não praticam a discriminação de forma ilegal, mas de acordo com as legislações criadas para legitimar a segregação racial (Almeida, 2020, pp. 83-87). O direito constitui, dessa forma, a concretização escrita de uma ideologia, peça fundamental para a pavimentação do racismo estrutural.

Muitos países criaram legislações que encarceravam os trabalhadores que descumprissem contratos de trabalho, punindo de forma branda os deslizes do empregador. O historiador Robert Steinfeld discorreu sobre a realidade inglesa no século XIX, marcada por uma legislação trabalhista punitiva e por um poder 
judiciário tendencioso. Steinfeld destacou ainda o papel do livret, na França e na Bélgica, na manutenção dos trabalhadores nas propriedades dos seus patrões. O trabalhador somente poderia procurar outro emprego quando o patrão devolvesse o seu livret, indicando que aquela pessoa havia cumprido todas as atribuições do seu contrato. Na França, a obrigatoriedade de trazer consigo o livret foi repelida apenas em 1890 (Steinfeld, 2001, pp. 243-244).

O caso da Guiana Inglesa é emblemático por mostrar a reafirmação dos pilares do racismo estrutural pela burocracia imperial britânica. A carta-denúncia mencionada no começo do texto criou uma oportunidade para a desconstrução - ou pelo menos para o questionamento - do racismo nas instituições da colônia. O ex-juiz George Des Voeux levantou os problemas do sistema imigratório colonial, e o ex-chefe de justiça Joseph Beaumont referendou as acusações do colega, fornecendo material necessário para algumas transformações na colônia. A Comissão de Inquérito enviada pelo Ministério das Relações Exteriores (Foreign Office) desqualificou as denúncias de Des Vouex, apontando que o juiz tinha feito acusações sem fornecer as devidas provas.

Os representantes da colônia visitaram 55 das 124 propriedades de Demerara que empregavam mão de obra asiática, e observaram as condições das habitações e dos hospitais que atendiam aos imigrantes. As visitas ocorriam sem aviso prévio, mas eram acompanhadas dos gerentes (managers) durante todo o momento. A comitiva ouviu funcionários do Departamento de Imigração, empregados do governo colonial, juízes, antigos moradores da região, fazendeiros, mercadores e funcionários das fazendas. No total, 46 pessoas foram ouvidas, sendo que nenhuma delas era imigrante de origem asiática. Também foram analisadas reportagens publicadas nos jornais The Colonist e The Creole, bem como documentos oficiais do governo, visando à complementação dos relatos das testemunhas. O relatório da comissão foi escrito por W. E. Frere, George Young e C. Mitchell (Ithell, 1871, pp. 16-17 e 380).

A Comissão de Inquérito realizou uma investigação com um número limitado de pessoas, confiou em jornais pró-fazendeiros e desconsiderou a opinião dos imigrantes sobre o assunto. Enquanto isso, a comissão enviada pelo governo chinês para investigar a situação dos seus súditos em Cuba entrevistou quase 1200 chineses para chegar a uma conclusão ${ }^{5}$. A Comissão de Inquérito desconsiderou as denúncias de Des Voeux por falta de provas e publicou uma lista com propostas que pouco mudavam a realidade do imigrante. A investi- 
gação mostra certa parcialidade e demonstra uma tendência do governo colonial em manter o sistema opressivo que subjugava o trabalhador asiático.

O relatório produzido pela comissão serviu para reforçar os instrumentos de poder dos fazendeiros, ao propor novas legislações que em nada resolviam os problemas daqueles trabalhadores. O estabelecimento do livret continuaria a oferecer possibilidades para que os empregadores abusassem da sua posição de poder. O relatório da comissão reproduz parte da ideologia racista contra os imigrantes asiáticos, ao reforçar a dificuldade deles de arrolar testemunhos e dar depoimentos verdadeiros. Afinal, esses trabalhadores cultivariam, segundo o relatório, "o respeito pela verdade" "asiática", e não pela verdade praticada pelos povos europeus. Os depoimentos dos imigrantes asiáticos não deveriam ser rejeitados na totalidade, e sim considerados com certa desconfiança (Ithell, 1871, p. 182).

\section{As INSTITUIÇÕES E O RACISMO}

James Crosby foi apontado em 1858 para o cargo de Agente Geral de Imigração e Protetor dos Imigrantes na Guiana, com a função de averiguar as condições de imigração e a obediência das regras dos navios que traziam os imigrantes para a colônia. Ele deveria informar outros juízes sobre o tratamento dos imigrantes, o pagamento dos salários e as punições recebidas nas fazendas. O funcionário agiu como um protetor dos imigrantes, investigando e reportando as denúncias mais graves ao governador. O empenho de Crosby enfureceu os fazendeiros, que convenceram o governador Francis Hinks, ocupante do cargo entre 1862 e 1869, a diminuir os seus poderes.

Quase todos os relatos sobre a imigração asiática na Guiana Inglesa mencionam a importância de James Crosby ${ }^{6}$. Edward Jenkins ressaltou o esforço do funcionário de averiguar a qualidade do tratamento hospitalar provido ao grupo e de registrar as mortes e os casamentos dentre os asiáticos. O trabalho do agente teria conseguido melhorar a situação dos imigrantes, que reconheciam em Crosby um protetor (Jenkins, 1871, pp. 203-204) Henry Kirke, ex-xerife de Demerara, lembrou que, mesmo após a sua morte, os imigrantes usavam o termo "ver o Sr. Crosby" quando buscavam a justiça (Kirke, 1898, pp. 72-73). Joseph Beaumont descreveu-o como alguém de personalidade independente e disposto a exercer uma influência benéfica, caso tivesse liberda- 
de para agir dessa forma (Beaumont, 2011, p. 112). Des Voeux relembrou da forma cortês e da paciência com que ele ouvia as reclamações e se dirigia aos imigrantes (Des Voeux, 1958, pp. 95-96).

As boas intenções de um funcionário não foram, contudo, suficiente para reverter as situações de abuso e abandono às quais os imigrantes asiáticos estavam sujeitos. O governador da Guiana mudou os procedimentos de investigação e determinou que as visitas às fazendas fossem realizadas pelos subagentes, e não mais pelo Agente de Imigração. James Crosby precisava obter autorização prévia para a visita e conseguir a liberação de recursos caso quisesse visitar as fazendas. A autorização ficava a cargo do governador da colônia, que estava empenhado em dificultar o trabalho de Crosby. O governador Hincks chegou a proibir expressamente que o Agente de Imigração visitasse as fazendas (Beaumont, 2011, p. 112; Kirke, 1898, p. 72).

A Comissão de Inquérito relatou as desavenças entre o Agente Geral de Imigração e o governador, que enviou várias queixas contra as ações de Crosby para o Colonial Office, com a acusação de desobediência. O governador determinou que todos os documentos, por mais insignificantes que fossem, deveriam ser enviados a ele, com uma breve explicação, antes que fossem remetidos a Londres. James Crosby recorreu a instâncias superiores, mas as suas reclamações foram ignoradas. Crosby foi suspenso do cargo várias vezes e deixado de lado pela burocracia colonial. O subagente, Mr. Gallagher, assumiu o posto de Agente de Imigração durante as suspensões e, na maioria das vezes, atendeu os interesses dos fazendeiros, de acordo com a apuração de Edward Jenkins ${ }^{7}$.

A perseguição sofrida por James Crosby revela a institucionalização do racismo no judiciário colonial britânico. Combater os abusos aos imigrantes de origem asiática significava desafiar uma estrutura de poder estabelecida. $\mathrm{O}$ Agente de Imigração desafiou os fazendeiros e teve o seu trabalho obstruído pelo seu chefe na hierarquia colonial. Os embates com o governador não eram mistério e apareceram nas memórias de ex-funcionários, na carta-denúncia, em textos da Sociedade Abolicionista Britânica e no relatório da Comissão de Inquérito. A diversidade das fontes mostra que órgãos oficiais e associações civis tinham ciência da situação, mas pouco fizeram para solucioná-la.

O direito serviu claramente como uma ferramenta usada pelos latifundiários para controlar socialmente os imigrantes asiáticos. A legislação permitia, por exemplo, que os fazendeiros prendessem os seus trabalhadores que se en- 
contrassem afastados da propriedade sob a acusação de deserção. Muitos imigrantes foram presos por negligência no trabalho, tendo o seu patrão como principal testemunha. A legislação fornecia um caminho legal para que os latifundiários exercessem poder sobre os seus contratados.

A arbitrariedade dos patrões era embasada pelos juízes, o que contribuía para a formação de um sistema jurídico e social que favorecia os latifundiários. Os imigrantes já enfrentavam naturalmente uma burocracia que impedia que eles processassem os seus empregadores. $\mathrm{O}$ deslocamento para povoamentos, onde podiam acessar a justiça, era dificultado pelos patrões, legitimamente amparados pelas leis. O idioma, por exemplo, apresentava uma outra barreira difícil de ser transposta. Os imigrantes eram obrigados a pagar \$ 24 por mês a um intérprete caso quisessem ajuizar uma ação contra os seus empregadores (Jenkins, 1871, p. 285). O valor equivalia a mais de seis meses de trabalho e constituía uma barreira financeira. Vale lembrar que os salários dos asiáticos chegavam a um quarto do valor recebido por trabalhadores de origem africana ${ }^{8}$.

Tais entraves eram conhecidos por todos e permitidos pela lei. Revela-se aí uma das facetas do racismo estrutural, que impede que chineses e indianos tenham o mesmo acesso ao judiciário que os seus patrões. Segundo Edward Jenkins, o número de queixas movidas pelos imigrantes contra os seus patrões na Guiana Inglesa não passava de 100, contra mais de 32 mil casos movidos pelos fazendeiros contra os seus empregados, entre os anos de 1865 e 1870 . A realidade nas Ilhas Maurício, por exemplo, seria bastante diferente daquela apresentada pela Guiana Inglesa. De acordo com Jenkins, o número de queixas apresentadas por imigrantes asiáticos era quase a mesma dos processos movidos pelos patrões nas Ilhas Maurício (Jenkins, 1871, p. 289).

As observações de Jenkins afirmam que existiram, dentro do Império Britânico, diferentes níveis de institucionalização do racismo. O autor não apresentou dados mais concretos para fundamentar a afirmação. As condições de vida dos imigrantes indianos nas Ilhas Maurício seria, no entanto, tema de uma Comissão Real de Inquérito enviada ao arquipélago em 1872. A comissão fora formada após o recebimento de uma denúncia apresentada por Adolphe de Plevitz em 1871, na qual também eram destacadas as péssimas condições dos imigrantes e a parcialidade do sistema judiciário. Plevitz era um latifundiário nascido na França que já havia publicado textos em jornais, com o pseudônimo de "Randim", e enviado petições a sociedades abolicionistas inglesas 
e ao governo imperial. A Comissão enviada às Ilhas Maurício confirmou os maus-tratos (Royal Commission of Inquiry... 1872).

Plevitz sofreu um ataque físico, foi alvo de petições e excluído da sociedade das Ilhas Maurício. A pressão dos latifundiários era grande nas duas colônias e, segundo Beaumont, a independência da justiça existia apenas na teoria, uma vez que os juízes tomavam as suas decisões sob o julgo da burocracia colonial. Aqueles que fossem tomados pelo "espírito de mártir" e contrariassem o interesse dos latifundiários seriam punidos (Beaumont, 2011, p. 30). Dois funcionários que se colocaram contra o sistema sofreram consequências nas suas carreiras. James Crosby foi colocado em segundo plano e não conseguiu mais escutar e proteger os imigrantes. Joseph Beaumont foi afastado das suas funções. George Des Voeux não trabalhava mais na Guiana Inglesa e, por isso, conseguiu manter o seu cargo no sistema colonial inglês. As denúncias realizadas por ele foram, no entanto, desmentidas pela Comissão de Inquérito por falta de provas.

Os casos citados não conseguiram subverter a ordem e transformar a realidade da Guiana Inglesa, revelando como atos individuais não conseguem desconstruir o racismo institucional devidamente estabelecido. Joseph Beaumont, inclusive, desenvolveu uma outra tese para justificar a corrupção do judiciário na colônia. A subserviência dos juízes aos fazendeiros não viria necessariamente da ameaça ou do medo de contrariar essa classe. Muitos deles estavam "impregnados" do que Beaumont chamou do "espírito autoritário dos fazendeiros em relação aos trabalhadores". A parcialidade viria da simpatia com a classe social dos fazendeiros (Beaumont, 2011, p. 108).

É difícil precisar qual fator pesa mais na decisão dos juízes - a simpatia pela classe social ou a pressão dos latifundiários, mas os dois fatores são relevantes. Não há como se desconsiderar a importância da ideologia na conformação do racismo estrutural. A ideologia molda o inconsciente dos indivíduos, de forma que a concepção de mundo e as ações das pessoas são perpassadas por noções preconceituosas diretamente associadas à raça (Almeida, 2020, p. 410). Os asiáticos eram vistos como mentirosos, pouco confiáveis e dissimulados, e tais concepções impregnavam as decisões de juízes, promotores e governadores.

Os documentos mostram como essa concepção era difundida entre os ingleses que visitavam ou moravam na Guiana. Henry Kirke, por exemplo, 
afirmou que os indianos nunca respondiam a verdade, mas aquilo que eles acreditavam que o arguidor queria ouvir (Kirke, 1898, p. 233). Edward Jenkins destacou que os indianos juravam dizer a verdade, mas aumentavam consideravelmente as narrativas (Jenkins, 1871, p. 250). A Comissão de Inquérito britânica considerava que a concepção de verdade asiática diferia da europeia, o que a colocava no dilema entre ouvir esses imigrantes como testemunhas e desconsiderar os depoimentos (Ithell, 1871, p. 183).

Os imigrantes carregavam uma reputação de mentirosos e poucos confiáveis e, segundo Jenkins, essa "fraqueza moral dos coolies" fazia com que muitos juízes acreditassem que as evidências apresentadas e os depoimentos prestados por um homem branco valiam muito mais do que os testemunhos relatados por dezenas de hindus. Segundo Jenkins, em muitos casos, os imigrantes, cientes da pouca credibilidade de suas palavras, teriam pago homens negros para reafirmarem as mesmas coisas que eles diziam. O próprio Des Voeux teria contado algumas situações nas quais ele suspeitara que a compra de testemunhas havia ocorrido (Jenkins, 1871, pp. 112 e 114).

Esse trecho levanta a suspeita de que a palavra de homens negros e mestiços valia mais do que os depoimentos dos imigrantes indianos. A documentação escolhida não nos permite realizar um levantamento preciso que identifique as nuances do racismo estrutural entre trabalhadores de origem africana, asiática ou europeia. Os textos destacam a exclusão das populações de origem asiática. Jenkins relata que os trabalhadores de todos os grupos étnicos desconfiavam dos magistrados (Jenkins, 1871, p. 326). Não vamos distinguir, nesse artigo, as nuances da discriminação. Ressaltamos, no entanto, como a ideologia que sustenta a discriminação deixou de ser um produto do imaginário e se transformou em um embasamento teórico para diversas práticas sociais. $\mathrm{O}$ racismo em relação a indianos e chineses foi naturalizado em práticas sociais, como o hábito de se desconsiderar o depoimento desses trabalhadores por falta de confiabilidade.

O racismo não precisa de uma ação consciente para existir, de um ato de discriminação específico. As condições estruturais e institucionais daquela sociedade estão encarregadas de definir quais indivíduos fazem parte de qual grupo, e quais são os comportamentos esperados por esses grupos. As pessoas são racializadas pelo sistema e, a partir daí, há a criação de códigos e conceitos associados a elas. Os magistrados tenderão a desconsiderar ou duvidar do de- 
poimento prestado por um imigrante asiático, quando contraposto ao relato de um administrador branco. A institucionalização do racismo acontecia sem alardes e penetrava o imaginário da sociedade.

O juiz deparava-se frequentemente com dois lados de uma verdade. Um lado era representado por um trabalhador ou por um grupo de trabalhadores asiáticos, fisicamente diferentes, culturalmente "exóticos" e supostamente inferiores. Esses trabalhadores falavam um idioma estranho e comunicavam-se por meio de intérpretes, que nem sempre traduziam as situações com o rigor necessário. O outro lado era composto por administradores, homens normalmente de origem escocesa, com certa instrução, que tinham chegado à Guiana há alguns anos para ocupar cargos de supervisores (overseer) (Ithell, 1871, p. 147). Os homens brancos eram oriundos do mesmo mundo dos juízes, falavam a mesma língua e conheciam as regras e os procedimentos aos quais estavam sujeitos.

A simpatia à qual Joseph Beaumont se referia era compreensível e provavelmente influenciava as decisões tomadas pelos magistrados. A denúncia realizada por Des Voeux extrapolava o campo da simpatia e revelava um sistema repleto de ameaças, jogos de poder e de estabelecimento de vínculos entre os juízes e os administradores das fazendas. A carta-denúncia expôs um nível de intimidade e de relacionamento estabelecido entre fazendeiros e magistrados que enviesava as decisões tomadas nas cortes de justiça e colocava em dúvida a imparcialidade do sistema jurídico.

As casas dos administradores das fazendas muitas vezes eram as únicas habitações em algumas regiões com o mínimo de conforto para receber uma autoridade. A maioria das localidades não contava com hotéis ou hospedarias para acomodar juízes, fiscais e agentes. Muitos juízes aceitavam a hospitalidade dos administradores das fazendas quando visitavam lugares distantes. Os magistrados dormiam, faziam as refeições e travavam diálogos com os donos das casas, criando, em alguns casos, vínculos de amizade. A própria Comissão de Inquérito aceitou a hospitalidade de muitos fazendeiros. De acordo com Jenkins, tal proximidade era vista pelos imigrantes como um empecilho para o exercício da imparcialidade do magistrado (Jenkins, 1871, pp. 104-105).

O ex-funcionário público inglês Henry Kirke descreveu os fazendeiros desse período como "os grandes homens da colônia”, "autocratas das suas próprias fazendas e de milhar ao redor". Eles eram juízes de paz localmente 
eleitos que se sentavam ao lado dos juízes da coroa nas cortes que julgavam crimes menores. A respeitabilidade desses fazendeiros era tamanha que banqueiros e comerciantes se curvavam diante deles (Kirke, 1898, p. 29). Edward Jenkins também destacou a influência desse grupo, mas assumiu um tom mais crítico daquele adotado por Henry Kirke. Segundo Jenkins, pessoas de diferentes classes e profissões confessaram-lhe, em particular, incômodo devido ao poder excessivo dos fazendeiros. Caberia, segundo ele, ao governador contrabalancear essa influência, mas a autoridade pouco fazia (Jenkins, 1871, p. 78). Jenkins relatou o incômodo de uma parcela relevante da população, enquanto Kirke lembrou desses fazendeiros com saudosismo e veneração.

Os administradores das fazendas compunham uma parcela relevante dos juris e certamente influenciavam as decisões dos demais membros. De acordo com Beaumont, os juris e a corte tendiam a decidir a favor dos fazendeiros em casos relacionados à disciplina nas fazendas, ao roubo de rum ou açúcar e aos danos a equipamentos. Grande parte desses processos desconsideravam as testemunhas de indianos e chineses. O ex-chefe de justiça Joseph Beaumont descreveu tal realidade e afirmou que a descrença nesses depoimentos não era pautada na experiência, mas em uma verdade pré-concebida.

Segundo Beaumont, na maioria das vezes os imigrantes eram desacreditados por outros membros da Coroa que chegavam à Guiana (Beaumont, 2011, p. 110). No entanto, atribuía-se credibilidade a esse grupo em casos específicos. Beaumont menciona um caso em que o procurador-geral pediu que o júri ignorasse os depoimentos apresentados pela defesa, baseando-se na tese de que não eram confiáveis. O caso, no entanto, apresentava uma grande contradição, pois as testemunhas de acusação, também coolies, deveriam ser ouvidas e levadas em consideração (Beaumont, 2011, p. 114). De acordo com o ex-juiz, as testemunhas coolies, provavelmente de origem indiana, eram confiáveis quando arroladas por um procurador de origem europeu, e desacreditadas quando convocadas por uma garota de origem asiática.

Aquele que fala tem a sua credibilidade determinada por sua raça. Grada Kilomba discorre a respeito de quem pode falar na sociedade, refletindo sobre a noção de que alguém em uma posição de subalternidade não pode falar de sua situação. Existem muitos silêncios dentro do regime repressivo do colonialismo e do racismo (Kilomba, 2019, p. 47). O exemplo acima revela quem pode falar e quem concede a autorização para que os imigrantes asiáticos pos- 
sam ser ouvidos. O testemunho desses trabalhadores foi legitimado e considerado a partir da chancela de um homem europeu, que convoca as testemunhas.

O racismo presente nas instituições estrutura um regime no qual certos grupos gozam de direitos e outros são privados de tais direitos. A desigualdade entre os diferentes grupos étnicos era naturalizada por essa sociedade. Joseph Beaumont relatou, em um outro trecho de seu livro, a discrepância no julgamento de dois casos, nos quais os assassinos pertenciam a povos diferentes. O primeiro deles refere-se ao homicídio de um capataz por um Li a ying - um trabalhador de origem chinesa. O assassinato ocorreu após provocações verbais e físicas iniciadas pelo capataz motivarem uma briga entre os dois, que culminou no assassinato do capataz pelo trabalhador chinês. $\mathrm{O}$ caso foi julgado pelo júri, que determinou a pena de morte ao réu.

O segundo caso envolveu a morte de um trabalhador também chinês, chamado Low-a-si. O imigrante alegou que estava doente e que, por isso, não poderia trabalhar naquele dia. O supervisor e os capatazes reagiram com brutalidade, batendo e chutando Low-a-si até a morte. Esse assassinato foi seguido de outros casos semelhantes na mesma fazenda, nos quais os trabalhadores apanharam brutalmente quando se declaravam doentes. Muitos deles foram obrigados a trabalhar sangrando, vomitando ou com cansaço evidente. Os perpetradores de tamanha violência não foram punidos, mesmo após terem cometido atos cruéis à luz do dia, diante de dezenas de pessoas (Beaumont, 2011, pp. 90-91).

As diferentes maneiras como a sociedade lidou com os dois casos explicita que o valor da vida de um indivíduo se relacionava à sua origem étnica. A justiça não era cega; enxergava claramente a cor da pele das vítimas e dos réus, atuando como uma ferramenta importante para subjugar os trabalhadores às vontades dos seus patrões. $\mathrm{O}$ assassinato de um capataz por um trabalhador era algo inaceitável e ameaçava, de certa forma, a ordem e o funcionamento das fazendas. $\mathrm{O}$ assassinato de imigrantes que aparentemente mostravam má vontade com o trabalho podia ser interpretado como um efeito colateral à manutenção da ordem e da produtividade naquelas propriedades.

A punição dos criminosos e a execução da justiça serviam aos interesses de uma determinada classe social. Pessoas que cometeram o mesmo crime poderiam ganhar a liberdade ou a condenação de acordo com a sua raça ou a sua influência social. A justiça estava a serviço dos fazendeiros, compondo uma 
parcela importante do racismo estrutural na Guiana Inglesa. O espancamento até a morte poderia nem sequer originar um processo, caso cumprisse a função de disciplinar a classe trabalhadora. Outros crimes, como o roubo, a negligência no trabalho e a ruptura de contrato culminavam frequentemente em punição para os trabalhadores, uma vez que cumpriam a mesma função disciplinar.

Os três crimes mencionados acima podiam ser facilmente forjados, pois bastava o depoimento dos patrões para se levantar as provas suficientes à acusação. A fragilidade das provas e o lado tendencioso da justiça levavam a um grande número de condenações dos trabalhadores de origem asiática. Joseph Beaumont apresentou dados pouco precisos, baseados em sua memória sobre as condenações na Guiana Inglesa. Segundo o ex-chefe de justiça, durante a sua gestão, aproximadamente 280 pessoas eram indiciadas anualmente, das quais 160 eram condenadas. Metade dos condenados eram imigrantes asiáticos sob o regime de contratos de trabalhos, dos quais aproximadamente 80 eram indianos e 80 chineses (Beaumont, 2011, p. 93).

Levantamentos populacionais na Guiana Inglesa mostram que a população total da colônia era de 193.491 pessoas. Os negros e os mestiços compunham a maioria da população, somando 122.862 indivíduos, seguidos dos indianos, que computavam um total de 48.363 indivíduos. Outros grupos minoritários eram os portugueses, 12.029; chineses, 6.880; e brancos, 2.903 (Lai, 1998, p. 302). Os dados apresentados por Joseph Beaumont nos permitem inferir que menos de $30 \%$ da população - a soma de chineses e indianos - seria responsável por mais da metade das condenações dos tribunais. A proporção é mais desigual ainda caso consideremos que os chineses, pouco mais de $3 \%$ da população, respondiam por mais de um quarto das condenações.

A realidade descrita guarda certas semelhanças com a situação vivida por chineses sujeitos a contratos de trabalho semelhantes em Cuba. O intelectual cubano José Antonio Saco publicou alguns números que mostravam a proporção de presos em relação ao universo populacional de diferentes grupos étnicos. A proporção de chineses presos era grande: um para cada 75 habitantes. Enquanto isso, a porcentagem era de um para cada 344 habitantes, quando consideramos os homens de cor livres; um para cada 448 habitantes, quando consideramos os brancos; e um para cada 1688 habitantes, quando consideramos os escravizados (Saco, 2001 [1862], p. 110). O grande número de imigrantes asiáticos presos em Cuba e na Guiana Inglesa nos leva a pensar que o en- 
carceramento era utilizado como estratégia de controle social pelas autoridades coloniais espanholas e britânicas.

Números como estes contribuem para se compreender a amplitude do racismo em relação aos trabalhadores asiáticos. O racismo, conforme lembrou Silvio de Almeida, também é um processo de constituição de subjetividades, intimamente ligadas a práticas sociais. As teorias raciais que discriminavam os diferentes povos construíam concepções de civilização e barbárie, que pressupunham a incapacidade de povos como chineses, indianos e africanos de viver em uma sociedade civilizada'. Os chineses, por exemplo, eram, de acordo com José Saco, filhos de "uma raça corrompida e perversa", que tinha pouco apreço pela vida (Saco, 2001, p. 110). O alto número de presos condiz com as concepções raciais compartilhadas naquele momento, que desumanizavam povos não europeus.

As teorias raciais criam concepções e verdades sobre grupos étnicos que contribuem para o alto número de condenações no que concerne a algumas populações. As estatísticas desfavoráveis aos povos não europeus reforçam a ideologia discriminatória e servem como argumento para a discriminação de determinados povos. Intelectuais e funcionários públicos encontram uma explicação "racional" para a desigualdade racial e para o tratamento diferenciado aos diferentes grupos que compõem aquela sociedade. $\mathrm{O}$ racismo estrutural exclui e julga com parcialidade os imigrantes asiáticos e, ao fazê-lo, cria números e estatísticas que reforçam o seu discurso segregador.

A ideologia racista torna-se, portanto, um sistema de ideias vivo, constantemente alimentado com observações cotidianas que estranham hábitos, condenam práticas sociais e associam comportamentos a verdades pré-concebidas. A estigmatização do outro circula entre as pessoas e cria raízes profundas dentro da comunidade, influenciando as decisões e as políticas tomadas dentro das instituições estatais. A racialização da sociedade naturaliza a discriminação e a violência contra os povos considerados inferiores. O castigo físico perpetrado por um funcionário branco da fazenda a um chinês ou a um indiano, que resultava em óbito, era percebido por alguns membros da sociedade como algo cotidiano, "normal". $\mathrm{O}$ assassinato deste mesmo funcionário por um imigrante asiático gera, contudo, revolta e acaba sendo devidamente punido.

As subjetividades criadas pela ideologia são alimentadas pelas estatísticas que parecem confirmar aquilo previsto em teoria. A maioria não se questiona 
sobre os motivos que levaram tantos asiáticos à prisão ou ao julgamento. Um levantamento realizado por Walton Look Lai revela que as três principais causas de prisão dos chineses em Trinidad - roubo, ruptura de contrato e andar sem portar certificado - podem ser facilmente manipuladas pelo empregador. As três infrações mencionadas responderam por 832 das 905 prisões dos chineses no ano de 1866, em Trinidad (Lai, 1998, p. 300).

A interpretação dos dados não importa tanto quanto a mensagem que se quer tirar deles - os chineses cometem mais crimes que outros povos. Tais subjetividades ancoram o pensamento dos procuradores gerais da Guiana Inglesa, que desconsideram os depoimentos dos trabalhadores asiáticos. A divisão do mundo entre "brancos" e "não brancos" facilita a distinção das testemunhas brancas como confiáveis e das não brancas como duvidosas.

Analisamos neste artigo o efeito do direito na construção do racismo estrutural por meio de artigos que revelaram o viés da justiça na Guiana Inglesa. Juízes, procuradores e advogados reproduziam estigmas raciais e julgavam os réus de acordo com a cor da pele. As leis serviram como uma extensão do poder dos fazendeiros produtores de açúcar de Demerara. Aqueles funcionários que tentavam romper com o sistema encontravam entraves na sua vida social e na hierarquia estatal. Os governadores da Guiana e até mesmo os enviados pela Grã-Bretanha para avaliar a situação da justiça da colônia foram coniventes com a situação. Seguimos, nesse texto, o pensamento de Silvio de Almeida, que destaca o papel de quatro pilares para a composição do racismo estrutural: política, economia, direito e ideologia. Discutimos como a ideologia penetra o âmbito do direito para o estabelecimento de uma exclusão em nome da lei.

\section{REFERÊNCIAS}

ALMEIDA, Silvio. Racismo estrutural. Coleção Feminismos Plurais. São Paulo: Ed. Jandaíra, 2020.

ANDERSON, Clare et al. Guyana's Prisons: Colonial Histories of Post-Colonial Challenges. The Howard Journal of Crime and Justice, v. 59, n. 3, pp. 335-349, 2020.

BEAUMONT, Joseph. The New Slavery: An Account of the Indian and Chinese Immigrants in British Guiana. Guiana: Caribbean Press, 2011 [1871].

ITHELL, W. D. British Guiana, 1871: The Commission of Inquiry into the Treatment of Immigrants; The Report of the Commissioners. Volume 4. Georgetown, Guiana Inglesa: L. M’Dermott “The Colonist Office”, 1871. 
COOLIE IMMIGRATION TO BRITISH GUIANA. Anti-Slavery Reporter, v. 6, n. 45, Londres, 1851.

CONNOLLY, Jonathan. Indentured Labour Migration and the Meaning of Emancipation: Free Trade, Race, and Labour in British Public Debate, 1838-1860. Past \& Present, v. 238, n. 1, pp. 85-119, 2018.

DES VOEUX, George. Carta de Mr. Des Voeux a Earl Granville, (Apêndice A) 1869. In: JENKINS, Edward "Gingx Baby". Coolies; His Rights and Wrongs. Londres: Strahan \& Cia, 1871. pp. 377-410.

DES VOEUX, G. Williams. Experiences of a Demerara Magistrate, 1863-1869. Georgetown; Demerara; British Guiana: The Daily Chronicle Ltd., 1948.

CHINESE EMIGRATION: Report of the Commission sent by China to Ascertain the Condition of Chinese Coolies in Cuba, 1874. Shanghai: Imperial Maritime Customs Press, 1876. Reimpressão. Taupei: Ch'eng Wen, 1970.

CLEMENTI, Cecil. The Chinese in British Guiana. Georgetown: The Caribbean Press, 2010 [1915].

DORSEY, Joseph C. Identity, Rebellion, and Social Justice Among Chinese Contract Workers in Nineteenth-Century Cuba. Latin American Perspectives, Riverside, EUA, v. 31, n. 3, pp. 18-47, 2004.

HELLY, Dénise. Ideologie et Ethnicité: Le chinois Macao à Cuba. Montreal: La Presse de L'Université de Montreal, 1979.

HU-DEHART, Evelyn. Chinese Coolie Labour in Cuba in the Nineteenth Century: Free Labor of Neoslavery. Contribution in Black Studies: A Journal of African and Afro-American Studies, v. 12, pp. 38-54, 1994.

JENKINS, Edward "Gingx Baby”. Coolies; His Rights and Wrongs. Londres: Strahan \& Cia, 1871.

KEEVAK, Michael. Becoming Yellow: A Short History of Racial Thinking. Princeton: New Jersey: Princeton University Press, 2011.

KILOMBA, Grada. Memórias da plantação: episódios de racismo cotidiano. Rio de Janeiro: Cobogó, 2019.

KIRKE, Henry. Twenty-five years in British Guiana. London: Sampson Low; Marston \& Company, 1898.

LAI, Walton Look. The Chinese in the West Indies, 1806-1995: a documentary history. Kingston, Jamaica: The Press University of the West Indies, 1998.

LAI, Walton Look. Indentured Labor, Caribbean Sugar: Chinese and Indian Migrants to the British West Indies, 1838-1918. Baltimore; London: The John Hopkins University Press, 1993.

LÓPEZ, Kathleen. Chinese Cubans: A Transnational History. Chapell Hill: The University of North Carolina Press, 2013.

NARVAEZ, Benjamin. Chinese Coolies in Cuba and Peru: Race, Labor, and Immigration, 1839-1886. Austin: The University of Texas at Austin, 2010. 
PASTOR. Humberto Rodriguez. Hijos del celeste império en el Peru (1850-1900): migración, agricultura, mentalidad y explotación. Lima: Gráfica Bellido, 1989.

PÉREZ DE LA RIVA, Juan. Los culíes chinos en Cuba, 1847-1880: contribución al estudio de la inmigración contratada en el Caribe. La Habana: Editorial de Ciencias Sociales, 2000.

SACO, Jose Antonio. Las estatísticas criminales de Cuba em 1862. In: Obras. Volumen

IV. La Habana: Ediciones Imagen Contemporánea, 2001. pp. 108-115.

SCOTT, Rebecca J. Slave Emancipation in Cuba: The Transition to Free Labor, 18601899. Pittsburgh, EUA: University of Pittsburgh Press, 2000.

SHERMAN, Taylor C. Tensions of Colonial Punishment: Perspectives on Recent Developments in the Study of Coercive Networks in Asia, Africa and the Caribbean. History Compass, v. 7, n. 3, pp. 659-677, 2009.

STEINFELD, Robert J. Coercion, Contract, and Free Labor in the Nineteenth Century. New York: Cambridge University Press, 2001.

VILLAFUERTE, Gonzalo Alonso Paroy. Los otros en el discurso. Construcciones y transformaciones discursivas en torno al inmigrante chino (Lima, 1849-1900). Tesis (Licenciado en Historia) - Facultad de Ciencias Sociales Lima: Universidad Mayor de San Marcos. Lima: Perú, 2016.

YOUNG, Elliott. Alien Nation: Chinese Migration in the Americas from the Coolie Era through World War II. Chapel Hill: The University of North Carolina Press, 2014. YUN, Lisa. The Coolie Speaks: Chinese Indentured Laborers and African Slaves in Cuba. Philadelphia, EUA: Temple University Press, 2008.

PHILLIPS, Anne Marie. Contracting Freedom: Governance and East Indian Indenture in the British Atlantic, 1838-1917. Dissertation (Doctor of Philosophy) - Department of History, Duke University. Durham, EUA, 2014.

ROYAL COMMISSION OF INQUIRY to Mauritius. Londres: 1872.

\section{NOTAS}

${ }^{1}$ Esse artigo é resultado da tese de Doutorado realizada sob a orientação da professora Regina Duarte Horta.

${ }^{2} \mathrm{O}$ periódico da Sociedade Abolicionista Britânica era contrário ao uso de dinheiro público para financiar a imigração e muitos artigos denunciavam essa prática. Ler: Coolie Immigration to British..., 1851.

${ }^{3}$ Muitos estudos analisaram a situação desses imigrantes no continente americano. Sobre a imigração chinesa para Cuba, ler: Helly, 1979; Hu-Dehart, 1994; López, 2013; Narvaez, 2010; Pérez de La Riva, 2000; Scott, 2000; Yun, 2008. Sobre imigração chinesa no Peru, ler: Pastor, 1989; Villafuerte, 2016. 
${ }^{4}$ Para maiores discussões sobre os contratos, conferir: Dorsey, 2004; Steinfeld, 2001; Young, 2014.

${ }^{5}$ A China enviou uma comissão investigativa a Cuba em 1874, com o intuito de averiguar as condições dos seus súditos no país. Aproximadamente 1170 imigrantes foram ouvidos pela comitiva, que publicou o relatório em 1877. O documento, publicado em inglês e francês, evidenciou a precariedade da vida dos chineses em Cuba e contribuiu para a proibição da migração de chineses endividados por meio de contratos de trabalho. Para maiores informações a este respeito, conferir: Chinese Emigration: 1970 [1876].

${ }^{6}$ Para saber mais a respeito do empenho de Crosby na defesa dos imigrantes, ver: Clementi, 1915, pp. 45 e 105, e Lai, 1993, pp. 81 e 139.

${ }^{7}$ As fontes destacaram a disputa entre James Crosby e o governador da Guiana Inglesa. Cf. Kirke, 1898, p. 72; Ithell, 1871, pp. 78-82; Jenkins, 1871, p. 219. Alguns trabalhos retomaram tal disputa. Conferir, por exemplo, Phillips, 2014, p. 116.

${ }^{8} \mathrm{O}$ relatório da Comissão de Inquérito relatou as remunerações para várias ocupações. Os asiáticos ganhavam, em média, um quarto do que as mulheres e os homens negros recebiam. Ithell, 1871, pp. 408, 409 e 412.

${ }^{9}$ Para saber mais sobre as concepções a respeito dos asiáticos por parte dos europeus, conferir Keevak, 2011.

Artigo submetido em 20 de abril de 2021. Aprovado em 30 de junho de 2021. 